\section{Familial mirror movements over five generations}

Sir,

Familial mirror movement (MM) is a rare condition and refers to involuntary movements that occur in homologous contralateral muscles during their voluntary (active) movement and are often observed in the upper extremities but rarely in lower extremities.

The case study in question is a large Persian-speaking family from the Isfahan province in the Southeast of Iran with MMs over five generations. In addition, the heredity pattern of the family was delineated and four cases in the family under study were selected and are presented in Table 1.

To date, this is the only largest family group with MMs that has been reported. Neurological and psychiatric examinations and brain and cervical MRI were normal in the study group; and MMs were determined by electromyography. Another thirteen cases were studied on the basis of their medical histories.

Their family tree was drawn by asking the eldest member of the family regarding the interfamily relationships [Figure 1].

The execution of strictly unilateral motor tasks requires restriction of motor output activity in the M1 contralateral to the voluntary movement. ${ }^{[1]}$ MMs are an interesting but often overlooked neurological soft sign. Persistence of MMs in adult life without any other neurological or behavioral problem as a familial event was noticed by Rasmaussen in 1993. Congenital MM in association with nonfluctuant palpebral ptosis and nocturnal enuresis have been described recently by Ruggieri et al., in 1999. ${ }^{[2]}$ The study carried out by the researchers reports and investigates the largest family group to date with MMs over five generations with 17 affected persons and describes four individuals within this group as case studies [Figure 1]. The term of MM was first applied in 1879 by Earl Nemeyer. But the definition of MM as involuntary, synkinetic mirror reversals of an intended movement of opposite

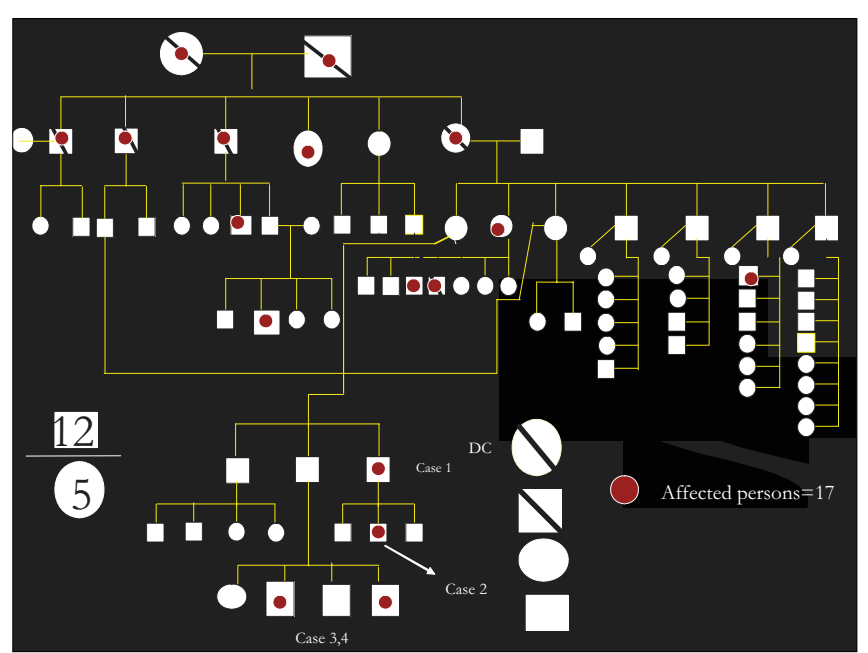

Figure 1: The family tree

side was coined by Cohen et al., in 1991. ${ }^{[3]}$ Depending on the cause, MM is classified as physiologic ( in a normal infant there is tendency for movements of one limb to be accompanied by similar involuntary movement of opposite limb). This tends to disappear before ten years of age, coincident with myelinization of corpus callosum; and symptomatic or pathological MMs, which is associated with several neurologic conditions such as, agenesis of corpus callosum, basilar invagination of skull, spina bifida occulta Friedrich's ataxia, Kallmann's syndrome, Usher syndrome, phenylketonuria, congenital hemiparesis, diabetes insipidus, mental retardation, CNS insult (tumor, CVA, SAH, trauma), ${ }^{[4]}$ schizophrenia, ${ }^{[5]}$ Parkinson disease, ${ }^{[6]}$ cerebral palsy, and obsessive compulsive disorder. ${ }^{[7]}$

Familial MM which is characterized by predominant or exclusive movement of hands especially the fingers is normally seen during active movements and rarely during passive movements. The MM will have lesser amplitude than that of voluntary movement, and occasional asymmetry of response mirroring is more evident on one side than the other. The increase in the MM with effort is noticeable early in life and nonprogressive after childhood may be hereditary (often due to autosomal dominance) or sporadic.

The literature regarding this particular phenomenon does not recommend surgery or drug treatment for the soft sign form of MM; however, cases under study have learned to decrease their movements with some

\begin{tabular}{|c|c|c|c|c|c|c|c|c|c|}
\hline Cases & M/F & $\begin{array}{l}\text { Upper } \\
\text { limb }\end{array}$ & $\begin{array}{l}\text { Lower } \\
\operatorname{limb}\end{array}$ & Distal & Proximal & $\begin{array}{c}\text { Exacerbated } \\
\text { by effort }\end{array}$ & $\begin{array}{c}\text { * Pain in } \\
\text { contralateral } \\
\text { limb by effort }\end{array}$ & $\begin{array}{c}\text { Fingers } \\
\text { dominantly } \\
\text { affected }\end{array}$ & $\begin{array}{c}\text { Exacerbated } \\
\text { with delicate } \\
\text { movements }\end{array}$ \\
\hline 1 & M & + & - & ++ & + & + & + & Middle & + \\
\hline 2 & $M$ & + & - & ++ & - & + & + & Middle & + \\
\hline 3 & M & + & - & ++ & + & + & + & No difference & + \\
\hline 4 & $M$ & + & - & ++ & + & + & + & No difference & + \\
\hline
\end{tabular}

* Limb with involuntary movement; M- male; severity of symptoms, + positive; ++ more than positive; - negative 
motor tricks.

It does advocate that the person stricken with MM should learn to minimize such movements by applying some motor ploys.

The aim of this study was the identification and presentation of the rare form of this soft sign and with due regards to the genealogical tree of the family under study, it seems as if the transmitted form of the disease is autosomally dominant.

\section{Naser Sharafaddinzadeh, Reza Bavarsad, Mah- yar Yousefkhah, Armaghan Moravej Aleali ${ }^{1}$}

Departments of Neurology and ${ }^{1}$ Clinical Research Center, Golestan Hospital, Jundishapour University of Medical Sciences, Ahwaz, Iran. E-mail: sharafaddinzadeh@yahoo.com

\section{References}

1. Carson RG. Neural Pathways Medicine: Bilateral interactions between the upper limbs. Brain Res Rev 2005;49:641-62.

2. Ruggieri V, Amartino H, Fejerman N. Congenital mirror movements: Three new cases of a rare condition. Rev Neurol 1999;29:731-5.

3. Cohen LG, Meer J, Tarkka I, Bierner S, Leiderman DB, Dubinsky RM, et al. Congenital mirror movements: Abnormal organization of motor pathways in two patients. Brain 1991;114:381-403.

4. Hermesdorfer J, Danek A, Winter T, Marquardt C, Mai N. Persistent Mirror movement: Force and timing of "Mirroring" are Task-dependent. Exp Brain Res 1995;104:126-34.

5. Hoy KE, Georgiou-Karisitianis N, Laycock R, Fitzgerald PB. Using transcranial magnetic stimulation to investigate the cortical origins of motor overflow: A study in schizophrenia and health controls. Psychol Med 2007;37:583-94.

6. Cineotta M, Borgheresi A, Balestrieri F, Giovannelli F, Ragazzoni A, Vanni P, et al. Mechanisms underlying mirror movements in Parkinson's disease: A transcranial magnetic stimulation study. Mov Disord 2006a;21:1019-25.

7. Bhattacharya A, Lahiri A. Mirror movement in clinical practice. J Indian Acad Community Med 2002;3:177-81.

Accepted on 13-11-2008 